\title{
ECOSSISTEMA EMPREENDEDOR: ANÁLISE DO PAPEL DA UNIVERSIDADE NO FOMENTO A NEGÓCIOS DE BASE TECNOLÓGICA
}

João Paulo Moreira Silva ${ }^{1}$

Liliane De Oliveira Guimarães ${ }^{1}$

${ }^{1}$ Pontifícia Universidade Católica de Minas Gerais - PUC Minas 


\section{ECOSSISTEMA EMPREENDEDOR: ANÁLISE DO PAPEL DA UNIVERSIDADE NO FOMENTO A NEGÓCIOS DE BASE TECNOLÓGICA}

Esse artigo teve por objetivo analisar a relação entre uma instituição de ensino superior e a geração de empreendimentos de base tecnológica. Esse objetivo se relaciona à literatura sobre ecossistemas empreendedores que identifica pilares, dentre eles as Instituições Universitárias, considerados importantes para a constituição de um ambiente propício ao empreendedorismo e negócios de base tecnológica. O artigo foi elaborado com base em dados preliminares, obtidos de dados documentais da universidade e entrevista com empreendedor fundador de start-up - estabelecido em Belo Horizonte, e ex-aluno da Universidade Federal de Minas Gerais. Os resultados mostraram que, de maneira geral, o empreendedor não reconhece ter obtido apoio e conhecimentos para formação e gestão do seu empreendimento no contexto universitário. Essa constatação nos leva a refletir se as Universidades não tem sido pouco empreendedoras no sentido de mostrar, com mais clareza, para seus públicos interno e externo, sua contribuição para o ecossistema empreendedor.

Palavras-chave: Ecossistemas empreendedores. Instituições Universitárias. Empresas de base tecnológica. Empreendedorismo.

\section{Introdução}

Altas taxas de empreendedorismo, e principalmente formação de empresas de crescimento acelerado, tem sido reconhecidos como fatores fundamentais no desenvolvimento econômico e social de diversas regiões (Isenberg, 2011). Uma vez que essa perspectiva se populariza nos contextos acadêmico e no empresarial e nações que contam com um ambiente empreendedor pulsante se destacam no cenário mundial, instituições governamentais de diversas localidades investem e estimulam a formação e desenvolvimento do denominado ecossistema empreendedor (Isenberg, 2010).

Um ecossistema empreendedor é formado por diversos atores ou pilares, tais como políticas governamentais, existência de capital financeiro e não financeiro, disponibilidade de infraestrutura e instituições universitárias, dentre outros. Considerando que desenvolvimento econômico - e a economia - se baseiam na geração, difusão e uso do conhecimento (Murovec \& Prodan, 2005), a literatura pesquisada destaca grande importância, para formação de um ecossistema empreendedor robusto, ao ensino de empreendedorismo e também às universidades e instituições de ensino (Gnyawali \& Fogel, 1994; Isenberg, 2011; Foster \& Shimizu, 2013). Considera-se que essas instituições, mais especificamente a universidade, podem, através de ações internas mas que se refletirão externamente, tornarem-se cada vez mais atuantes no desenvolvimento e amadurecimento de um ecossistema empreendedor, ao mesmo tempo em que se tornam verdadeiramente universidades empreendedoras (Etkowtiz, 2001).

No Brasil, os números que avaliam o ecossistema empreendedor são, no geral, negativos e demonstram deficiências em diversos pilares, apesar de possuir um desempenho superior em alguns aspectos que a média dos BRICS - grupo formado por Brasil, Rússia, India, China e África do Sul. Até mesmo os indicadores positivos são controversos, como é o
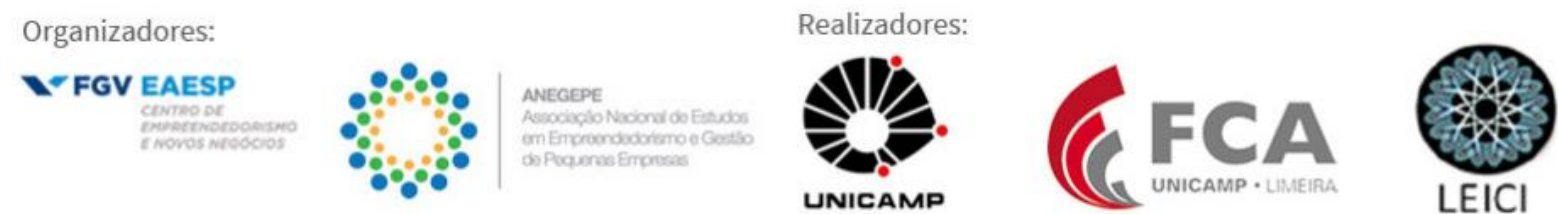
caso das habilidades necessárias para se iniciar um novo negócio, uma vez que, a nível individual, várias pessoas afirmam possuir as habilidades necessárias para tal fim, mas, institucionalmente, o país possui um gargalo com relação aos níveis de educação técnica e superior. Soma-se a isso baixos níveis de matrículas em universidades e escolas técnicas (Júnior, Autio, Morini, Gimenez \& Dionísio, 2016).

De acordo com Júnior, Autio, Morini, Gimenez e Dionísio (2016) o principal problema do ecossistema empreendedor nacional diz respeito à falta de cooperação entre as universidades e centros de pesquisa e o indivíduo empreendedor. As variáveis de aspecto tecnológico e de inovação também são consideradas de baixo desempenho, devido à falta de cooperação entre as universidades, o governo e a indústria. Como consequência disso, o empreendedorismo brasileiro possui baixas taxas de empresas nascentes de crescimento rápido, o que, na visão dos especialistas, não contribui para promover impactos na economia de forma significativa,

Por fim, o ecossistema empreendedor brasileiro é criticado por ainda apresentar as deficiências relativas à capacidade empreendedora e à cultura empreendedora vigente. A capacidade empreendedora, depende de dois fatores: a presença de educação destinada ao empreendedorismo e fluxos migratórios que tragam ao país profissionais qualificados (OCDE, 2011). Quanto à educação formal, o país não possui capacitação para o empreendedorismo em quase a sua totalidade. Os cursos de Administração, Economia e Engenharias presentes no país seguem a linha dos países de economia transicional (Habibov, Afandi \& Cheung, 2016), onde "são limitados à educação clássica no desenvolvimento de funcionários que são treinados para serem subordinados em grandes organizações - no Brasil, sinônimo de sucesso profissional” (Arruda, Nogueira, Cozzi \& Costa, 2015, p. 21). É possível ressaltar também o descompasso que existe no país entre a pesquisa realizada na Universidade e os empreendedores. A criação de conhecimento é realizada no país, mas o problema maior reside na sua difusão, uma vez que parece existir desconexão entre o conhecimento produzido no contexto universitário e operacionalização/comercialização da inovação pelas empresas (Arruda et al, 2015).

É nesse contexto que a presente pesquisa se insere, buscando, ainda de maneira preliminar, como excerto de uma pesquisa mais ampla sobre o ecossistema empreendedor, analisar a relação entre uma instituição de ensino superior e a geração de empreendimentos de base tecnológica, mais especificamente na ótica dos empresários, sobre os recursos disponibilizados por esses agentes de ensino foram importantes ao seu desenvolvimento empreendedor.

Dessa forma, esse artigo está composto por mais três seções além desta. Inicia-se, no referencial teórico, discutindo os termos ecossistema empreendedor e universidade empreendedora. Em seguida, no item 3, especifica-se a metodologia utilizada na realização da pesquisa e, por fim, no item 4, apresenta-se a descrição e análise dos dados. No item 5, são estabelecidas as principais conclusões e considerações finais.

\section{Referencial teórico}

\subsection{Empreendedorismo e ecossistema empreendedor}

A relação das organizações com determinada região é amplamente discutida por uma literatura extensa e farta. Desde o início do século XX, Alfred Marshall e o estudo das externalidades positivas geradas pelas aglomerações industriais trouxe à discussão acadêmica
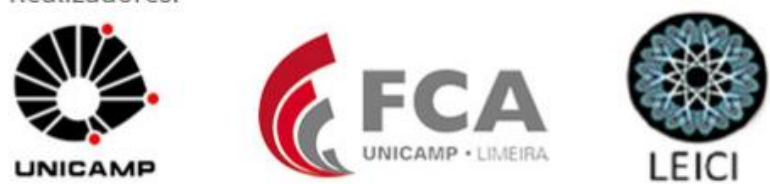
os ganhos que poderiam ser conquistados pelas empresas que gozassem de proximidade física a outras semelhantes e complementares. Os principais ganhos seriam desde vantagens em custos, até spillovers de conhecimento, os catalizadores de inovação (Ingstrup, Freytag e Damgaard, 2009).

Os anos 90 viram aumentar as pesquisas científicas endereçadas à aglomeração de empresas e seus sinônimos, concentrações geográficas e os ditos clusters (Ingstrup et al, 2009). Nessa perspectiva, foram analisadas a Rota 128 e o Vale do Silício concluindo-se que, apesar das características embrionárias semelhantes - relação direta com universidades, benefícios advindos de gastos públicos em aparato militar e atuação de capitalistas de risco -, os dois polos tecnológicos mantinham aspectos gerenciais distintos. Enquanto a Rota 128 mantinha divisões hierárquicas verticais e atitude hostil às inovações externas às organizações, o Vale do Silício atuava de forma contrária, aproveitando ações inovadoras tanto internas quanto externas à empresa. Tais fatores teriam relação direta no menor desempenho do primeiro em relação ao segundo. A cultura do ambiente passou a ser reconhecida como fator chave para o sucesso dos polos tecnológicos industriais (Saxenian, 1990; Mason e Brown, 2014)

O ambiente então, poderia, junto às competências adquiridas pelos indivíduos, serem conducentes ao empreendedorismo. Gnyawali e Fogel (1994) investigaram o que denominaram de ambiente condutivo ao desenvolvimento de novos negócios, indicando que seria "uma combinação de fatores que desempenham um papel no desenvolvimento do empreendedorismo" (Gnyawali e Fogel, 1994, p.44). Os fatores identificados pelos autores como determinantes para altas taxas de empreendedorismo foram agrupados em políticas governamentais, condições socioeconômicas, habilidades empreendedoras e nos negócios, apoio financeiro, e por fim, apoio não financeiro

Posteriormente, de caráter mais atual e levando em consideração o ambiente dinâmico do século XXI - onde o conhecimento organizacional tornou-se um ativo fundamental para as organizações (Murovec \& Prodan, 2009) e os arranjos de empresas e o ambiente que as integram passaram a ser identificados como construtos vinculados ao conhecimento e à inovação (Ingstrup et al, 2009) -, foi desenvolvida a abordagem de ecossistema empreendedor, que, segundo seus próprios autores, teria como objetivo representar referência para o desenvolvimento econômico de dada região. Tal abordagem é tratada como uma estratégia economicamente viável que torna possível estimular a prosperidade econômica, tornando-se um complemento ou até mesmo uma pré-condição à clusters, economias baseadas em conhecimento e sistemas pautados pela inovação (Isenberg, 2011).

Segundo Isenberg (2011), o ecossistema empreendedor é formado pelos domínios: (i) políticas públicas; (ii) financiamento; (iii) cultura; (iv) suporte; (v) capital humano; e (vi) mercados. Mason e Brown (2014), valendo-se das ideias de Isenberg (2011), ampliam a discussão sobre o ecossistema empreendedor, apontando, além de atores, as interações dos mesmos (2014), ou seja, um conjunto de atores interconectados - existentes e potenciais -, como organizações empreendedoras; instituições diversas - desde o poder público, universidades e empreendedores seriais -, que atuam de maneira integrada, formal ou informalmente, coordenando o desempenho do ambiente empreendedor local.

$\mathrm{Na}$ verdade, o modelo de Isenberg (2011) apresenta alguns atores/domínios até então esquecidos pelos estudos anteriores, mas importantes para a compreensão do ambiente

Organizadores:

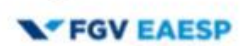

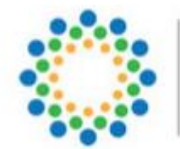

ANEGBE

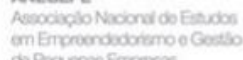
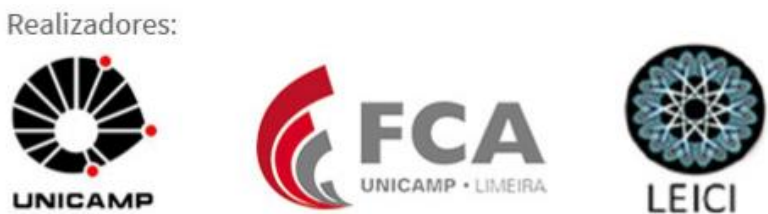
empreendedor. Entretanto, por outro lado, falha na especificação de laços causais entre as interações. Ou seja, não há no modelo indicações de quais domínios causam determinada consequência.

Um ecossistema empreendedor poderá estar direcionado a um tipo de indústria em específico ou apoiar diferentes setores. Além disso, apesar de possuir referência com o espaço geográfico (Isenberg, 2010) não estão confinados a tal, nem mesmo relacionado a um determinado tamanho de cidade (Mason \& Brown, 2014). Um ecossistema próspero também deverá posicionar o setor privado da economia como ator base do ecossistema (Isenberg, 2010), colocando as grandes corporações e os empreendimentos nascentes lado a lado.

Por ser contrário à uma mera replicação de ecossistemas bem-sucedidos, o modelo de Isenberg (2011) registra características mais genéricas quando comparado ao modelo integrado de ambiente empreendedor de Gnyawali e Fogel (1994), inclusive ressaltando que o empreendedor como ator central do ecossistema pode ser um equívoco - quando o foco se torna exclusivamente o empreendedor, em detrimento de se analisar a infraestrutura do seu entorno (Isenberg, 2016).

Mason e Brown (2014) ressaltam que o modelo elaborado por Isenberg (2011) incorpora diversos temas anteriores da literatura sobre desenvolvimento regional e empreendedorismo - incluindo a percepção de antigos arranjos como ecossistemas atuais -, mas com alguns aspectos distintos das anteriores, como o foco na atividade empreendedora e nas empresas de crescimento rápido.

Uma vez que existem diferentes modelos de ecossistemas (Mason e Brown, 2014), o proposto por Foster e Shimizu (2013) representa um dos muitos modelos de ecossistemas concebidos por instituições governamentais (Isenberg, 2016). A partir da percepção de que muitas análises e estudos de ecossistemas não levavam em conta evidências coletadas diretamente dos empreendedores, além das inconsistências entre as políticas e ações empreendedoras de diferentes ecossistemas, os autores apontaram os pilares de um ecossistema que consideram com maior relevância para facilitar o sucesso dos negócios. Dessa forma, os autores chegaram a oito pilares principais como determinantes de um ecossistema empreendedor, sendo eles: mercados acessíveis, força de trabalho, fontes de financiamento, sistemas de suporte - como mentores e analistas -, estrutura regulatória e infraestrutura, educação e treinamento, grandes universidades catalisadoras e suporte cultural. Ademais, para o florescimento de novos empreendimentos, ressaltam, os três pilares principais: (i) mercados acessíveis; (ii) força de trabalho e (iii) fontes de financiamento.

O Quadro 1, expõe, de maneira sintética, os elementos constitutivos de cada um dos modelos de ecossistemas citados anteriormente. É possível perceber, conforme as publicações se sucedem, que algumas subáreas dentro dos domínios acabaram por tomar corpo e importância para se tornarem um conjunto a parte ou novo domínio, como é o caso da educação e treinamento com a participação das grandes universidades. Citada tanto por Gnyawali e Fogel (1994), quanto por Isenberg (2011) como aspectos característicos do empreendedor, a educação e treinamento e grandes universidades (Foster e Shimizu, 2013) passam a se constituir em pilar relevante do ecossistema. Cabe destacar que os três modelos são unânimes quanto a necessidade de treinamentos específicos para o empreendedor. 


\begin{tabular}{|c|c|c|c|}
\hline & $\begin{array}{c}\text { Gnyawali e Fogel } \\
(1994)\end{array}$ & Isenberg (2011) & Foster e Shimizu (2013) \\
\hline $\begin{array}{l}\text { Políticas } \\
\text { públicas }\end{array}$ & $\begin{array}{l}\text { Legislação facilitadora e } \\
\text { promotora ao } \\
\text { empreendedorismo. }\end{array}$ & $\begin{array}{lr}\text { Liderança: } & \text { suporte inequívoco } \\
\text { pautado } & \text { em legitimidade. } \\
\text { Governo: } & \text { instituições e } \\
\text { estrutura } & \text { regulatória } \\
\text { facilitadora. Apoio financeiro e } \\
\text { institutos de pesquisa. }\end{array}$ & $\begin{array}{l}\text { Acesso à infraestrutura básica e } \\
\text { telecomunicação. Incentivos } \\
\text { fiscais e legislação facilitadora. }\end{array}$ \\
\hline $\begin{array}{l}\text { Financi } \\
\text { amento }\end{array}$ & $\begin{array}{l}\text { Acesso à capital de } \\
\text { risco, fontes alternativas } \\
\text { de financiamento e } \\
\text { empréstimo a baixo } \\
\text { custo. }\end{array}$ & $\begin{array}{l}\text { Acesso à capital de risco, } \\
\text { micro empréstimos e mercados } \\
\text { de capitais, investidores anjo, } \\
\text { amigos e família. }\end{array}$ & $\begin{array}{l}\text { Acesso à capital de risco e } \\
\text { dívida. } \\
\text { Participação } \\
\text { investidores anjo, amigos } \\
\text { família. }\end{array}$ \\
\hline $\begin{array}{l}\text { Cultura } \\
\text { e } \\
\text { Sociedade }\end{array}$ & \begin{tabular}{lr}
\multicolumn{2}{l}{ Diversidade de atividade } \\
econômica e & postura \\
empreendedora & da \\
sociedade. &
\end{tabular} & 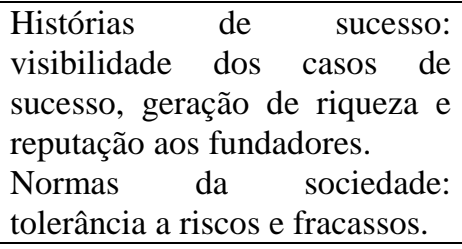 & $\begin{array}{l}\text { Tolerância à falhas e ao risco; } \\
\text { histórias de sucesso e imagem } \\
\text { positiva do empreendedorismo. } \\
\text { Cultura de pesquisa e celebração } \\
\text { da inovação. Preferência pelo } \\
\text { auto-emprego. }\end{array}$ \\
\hline $\begin{array}{l}\text { Instituições } \\
\text { de Suporte }\end{array}$ & $\begin{array}{l}\text { Infraestrutura, redes de } \\
\text { negócio e serviços de } \\
\text { mentoria e } r \text { apoio } \\
\text { governamental } r \text { para } \\
\text { P\&D às pequenas } \\
\text { empresas }\end{array}$ & $\begin{array}{l}\text { ING's: empreendedorismo em } \\
\text { ONG's; associações de apoio e } \\
\text { competições. Existência de } \\
\text { profissôes de apoio e } \\
\text { infraestrutura }\end{array}$ & $\begin{array}{l}\text { Mentores e conselheiros; } \\
\text { incubadoras e aceleradoras. } \\
\text { Serviços profissionais e redes de } \\
\text { parceiros empresariais. }\end{array}$ \\
\hline $\begin{array}{l}\text { Capital } \\
\text { Humano }\end{array}$ & $\begin{array}{l}\text { Educação técnica, } \\
\text { vocacional } \\
\text { empresarial. Programas } \\
\text { de treinamento sobre o } \\
\text { tema e disponibilidade } \\
\text { de informações }\end{array}$ & 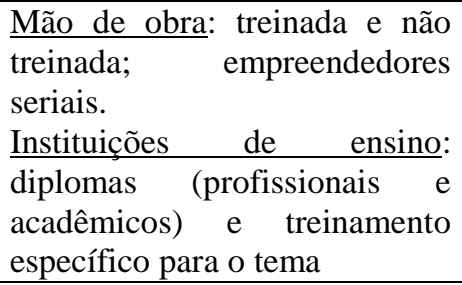 & $\begin{array}{l}\text { Experiência em organizações } \\
\text { empreendedoras; terceirização e } \\
\text { força de trabalho imigrante. } \\
\text { Talento técnico e em gestão. }\end{array}$ \\
\hline Mercados & & $\begin{array}{l}\text { Clientes } \text { iniciais: early } \\
\text { adopters para provar o } \\
\text { conceito; acesso aos primeiros } \\
\text { comentários e canais de } \\
\text { distribuição. } \\
\text { Redes: redes de } \\
\text { empreendedores e corporações } \\
\text { multinacionais. }\end{array}$ & 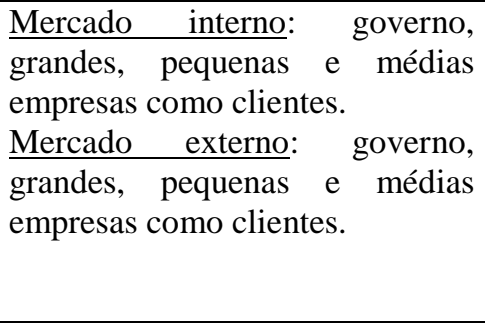 \\
\hline $\begin{array}{l}\text { Educação } \\
\text { e treina } \\
\text { mento }\end{array}$ & & & $\begin{array}{l}\text { Força de trabalho disponível com } \\
\text { educação pré-universitária e } \\
\text { universitária. Grandes } \\
\text { universidades promovendo } \\
\text { cultura empreendedora. }\end{array}$ \\
\hline
\end{tabular}

Fonte: adaptado de Gnyawali e Foster (1994), Isenberg (2011) e Foster e Shimizu (2013)

\subsection{Instituições Universitárias e o fomento ao empreendedorismo}

Conforme ressaltado, a Universidade atualmente ocupa papel importante no fomento e desenvolvimento do empreendedorismo. Muito disso deve-se ao fato de a Universidade

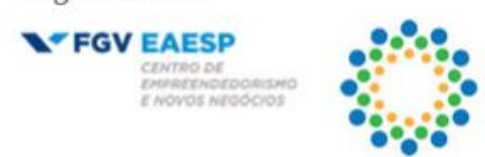


contemporânea estar inserida em um contexto dinâmico com outros atores, mais especificamente a indústria e o governo (Etkowtiz \& Leydesdorff, 2000); formando um sistema capaz de, em conjunto, promover o desenvolvimento tecnológico, econômico e social.

A relação mais próxima entre a Universidade, a Indústria e o Governo em uma perspectiva dinâmica, que resulta numa maior integração de objetivos e projetos, é chamada de abordagem da Hélice Tríplice (Etkowtiz \& Leydesdorff, 2000). Nessa perspectiva, a geração de novas empresas para a economia do conhecimento tornou-se objetivo formal de instituições universitárias diversas, assim como a comercialização de tecnologia e conhecimento viabilizados por empresas (Etkowitz, 2001).

A interdependência e as relações estreitas entre os três atores acima citados, formam a base da atual universidade empreendedora. Tal modelo de universidade pode ser definido como "uma estrutura e função acadêmica que é revisada através do alinhamento do desenvolvimento econômico com pesquisa e ensino como missões acadêmicas" (Etkowitz, Webster, Gebhardt \& Terra, 2000). A universidade empreendedora amplia o conceito de empreendedorismo para além do mundo dos negócios, instituindo o empreendedorismo a níveis educacionais, retirando o aspecto empreendedor do âmbito individual e o projetando também em âmbito coletivo (Etkowitz et al, 2000; Clark, 2001; Gibb, 2002) A Universidade empreendedora, cabe ressaltar, não irá servir apenas à geração de novos negócios em ciências e tecnologia, mas se constitui em um processo e nova mentalidade disseminados em toda a instituição (Clark, 2001).

A Universidade Empreendedora será constituída então por cinco elementos (Etkowitz, 2004 e Aranha \& Garcia, 2013): (i) capitalização, onde o conhecimento gerado torna-se a base de processos de desenvolvimento econômico e social; (ii) interdependência, baseada na interação próxima com a indústria e o governo; (iii) independência, reforçando a não dependência da universidade a outras instituições; (iv) hibridização, característica que ressalta a geração de organizações híbridas como resolução da difícil tarefa de ser independente e possuir interdependência, e por fim; (v) reflexividade, uma renovação contínua da estrutura interna da universidade conforme seus relacionamentos com os outros atores se modificam.

Segundo Etkowitz, Webster, Gebhardt e Terra (2000), a transformação da instituição em empreendedora deverá ocorrer a partir de quatro processos: (i) transformação interna, com a redefinição e ampliação das tarefas tradicionais de ensino e pesquisa; (ii) impacto transinstitucional, devido ao novo equilíbrio entre as esferas institucionais; (iii) processos de interface, através da criação de redes de contato e negociação entre os atores, e, por fim, (iv) efeitos recursivos, voltados à inovação e criação de novas organizações, elevando a instituição universitária à líder regional.

A educação empreendedora também deverá representar objetivo da Universidade Empreendedora, conforme ressalta a literatura sobre o tema. A transformação da universidade exige a identificação das ações necessárias para que o conhecimento gerado na Universidade seja direcionado ao processo de inovação, e, para isso, a educação empreendedora é fundamental (Tornatzky \& Rideout, 2014). No Brasil, apesar da melhora nos últimos anos, apenas $28,4 \%$ dos universitários já cursaram alguma disciplina diretamente relacionada ao empreendedorismo (SEBRAE, 2016).
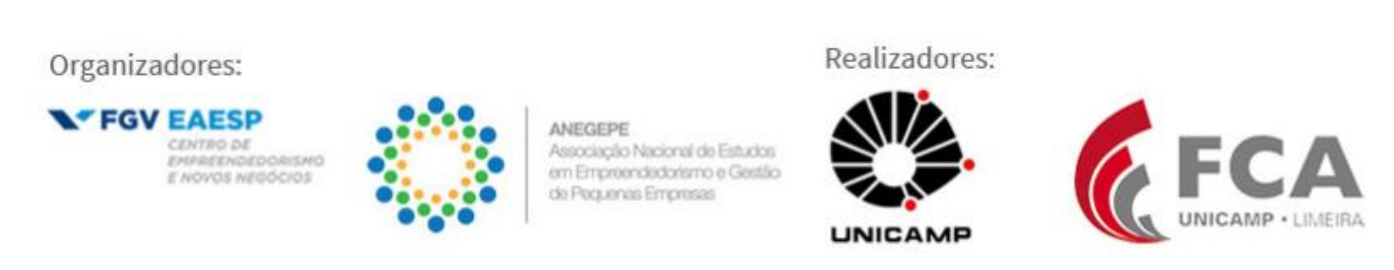
Tornatzky e Rideout (2014) salientam que, atualmente, existem duas tendências na educação empreendedora, sendo a primeira a oferta de disciplinas na grade curricular dos cursos, e a outra os programas co-curriculares, como fóruns, competições, serviços de incubação, mentorias, entre outros. Tais tendências anseiam superar o currículo de educação tradicional - prática comum das universidades brasileiras - que ainda priorizam alocar os alunos graduados em organizações burocráticas, industriais ou governamentais. (Etkowitz et al, 2000). Cabe ressaltar que o ensino empreendedor e a sua relação com a maior propensão a empreender ainda possui resultados difusos e é tema de acalorados debates (Chen, Hsiao, Chang, Chou, Chen \& Shen, 2013; Premand, Brodmann, Almeida, Grun \& Barouni, 2016; Habibov et al, 2016; Jabeen, Faisal \& Katsioloudes, 2017). Ao mesmo tempo, parece haver certo consenso de que as práticas de ensino de empreendedorismo são ultrapassadas, confusas e carecem de base teórica consistente (Gibb, 2002; Anderson \& Ronteau, 2017). Enquanto o ensino em sala de aula, dentro de um escopo curricular, traz resultados pouco conclusivos, a educação empreendedora mais ampla e por tempo mais longo, disseminada durante o curso e que conclui com a elaboração de um negócio tangível traz efeitos positivos à prática empreendedora. (Premand et al, 2016).

As incubadoras, na esfera de práticas co-curriclares (Tornatzky \& Rideout, 2014), são tidas pelos estudantes como segunda ação mais importante no apoio do empreendedorismo universitário (SEBRAE, 2016), priorizam empresas e empreendimentos de base tecnológica e são consideradas comuns às Universidades Empreendedoras (Etkowitz, 2003; Ferreira, Soria \& Closs, 2012; Aranha \& Garcia, 2013; Chais \& Machado, 2015; Zarate-Hoyos \& LariosMeoño, 2015). No Brasil, universidades que perseguem o objetivo de se constituírem em universidade empreendedora ampliando suas práticas de educação e estimulando a geração de organizações tecnológicas por meio das incubadoras, são bem vistas por empresários e pela sociedade (Ferreira et al, 2012; Chais \& Machado, 2015).

A transferência de tecnologia, por sua vez, será o mecanismo da exploração comercial das pesquisas realizadas pela instituição, e consequente diversificação de renda da universidade. Segundo Tortatzky e Rideout (2014), uma das tarefas de maior complexidade da Universidade Empreendedora será organizar, internamente, as pessoas certas para a geração e disseminação do conhecimento produzido pela instituição. Usualmente, essa disseminação ocorre em escritórios de transferência de tecnologia, que em maior ou menor grau, prospectam, recebem, ofertam e negociam as tecnologias disponíveis na universidade (Ferreira et al, 2012; Aranha \& Garcia, 2013; Chais \& Machado, 2015; Ortega, 2016). Após a criação de grupos de pesquisa e de um escritório de integração, responsável por gerenciar os contatos da instituição e a formalização dos processos, o escritório de transferência de tecnologia identificará, consolidará a patente e irá gerar as licenças obrigatórias para a comercialização.

De acordo com Philpott, Dooley, O’Reilly e Lupton (2011), as ações que uma universidade pode realizar para alcançar os objetivos de uma universidade empreendedora com base no modelo da tríplice hélice - desenvolvimento econômico regional -, poderão ser alocados em um espectro que distinguirá dois polos de iniciativas: fortes e fracas. Cada tipo contribuirá à sua maneira para o alcance dos objetivos da Universidade Empreendedora, conforme destacado na Figura 1.
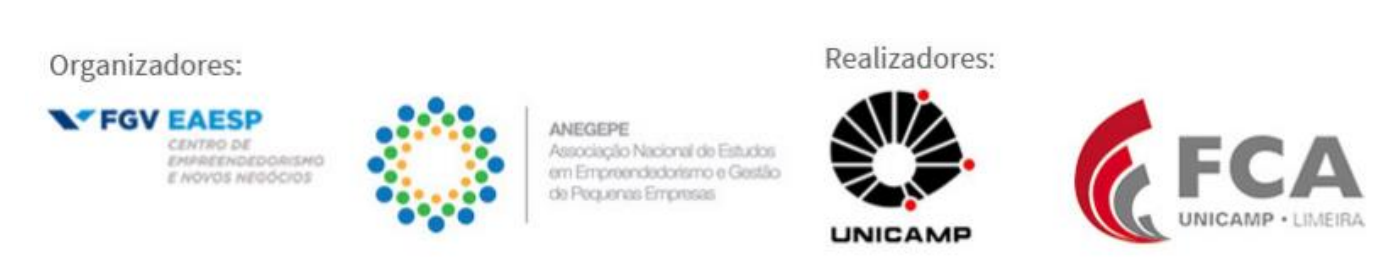

UNICAM

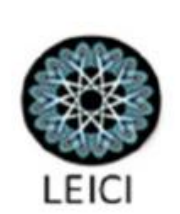


Figura 1 - Espectro de atividade empreendedora

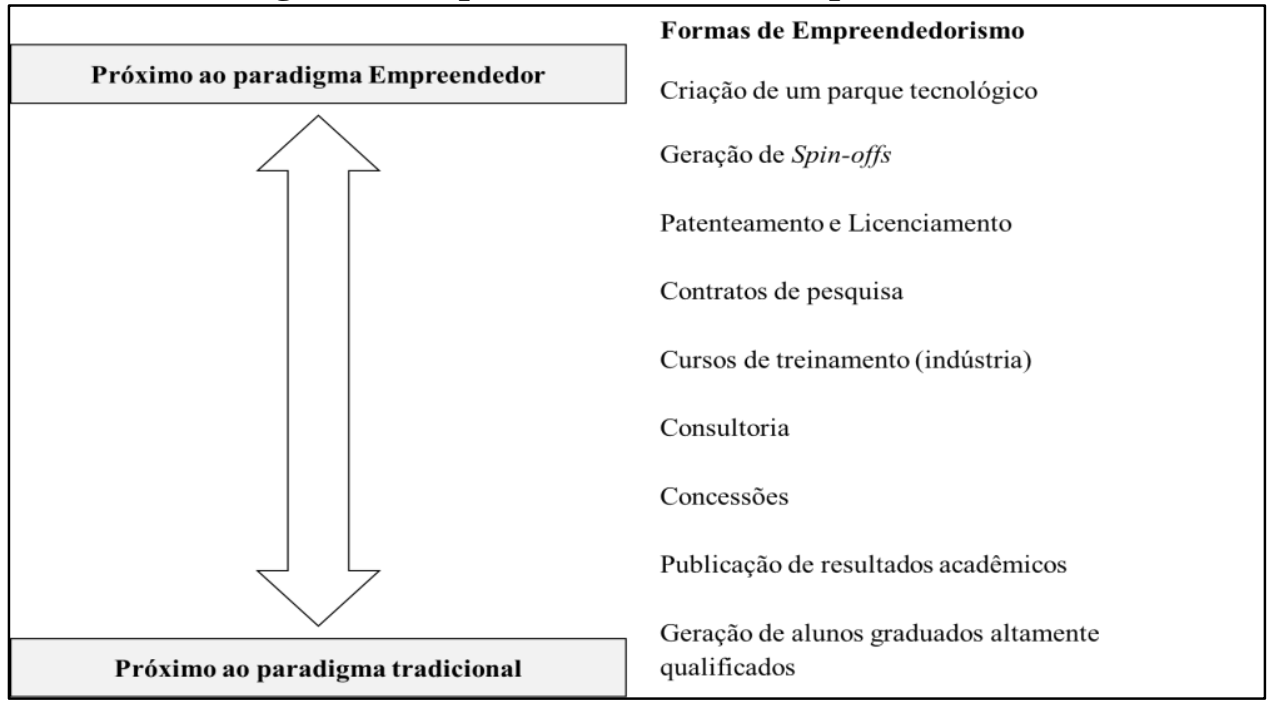

Fonte: adaptado de Phillpott, Dooley, O'Reilly e Lupton (2011)

Concluindo, a revisão da literatura pertinente ao tema nos possibilitou elaborar o modelo teórico que foi utilizado na pesquisa empírica. O modelo teórico de uma investigação tem como consequência o aumento da validade interna do estudo (Yin, 2005), uma vez que se refere à presença de relação causal entre as variáveis e resultado. A estrutura ilustra um raciocínio lógico que foi utilizado para a análise e sustentação dos resultados da investigação (Dubois \& Gibbert, 2010).

Quadro 2 - Categorias definidas para análise dos dados

\begin{tabular}{|c|c|c|}
\hline Categoria & Exemplos & Referências \\
\hline $\begin{array}{l}\text { Estrutura } \\
\text { física }\end{array}$ & $\begin{array}{l}\text { Incubadoras, } \\
\text { aceleradoras, co- } \\
\text { workings, salas de } \\
\text { estudo e extensão }\end{array}$ & $\begin{array}{l}\text { Etkowitz (2004); Ferreira, Soria e Closs (2012); Aranha, Garcia, } \\
\text { (2013); Zarate-Hoyos; Larios-Meoño, (2015); Arruda, Nogueira, } \\
\text { Cozzi e Costa (2015); Ortega (2016); Júnior, Autio, Morini, } \\
\text { Gimenez e Dionísio, (2016); }\end{array}$ \\
\hline $\begin{array}{l}\text { Apoio } \\
\text { técnico }\end{array}$ & $\begin{array}{l}\text { Curso de } \\
\text { Empreendedorismo } \\
\text { (em grade curricular), } \\
\text { cursos e treinamento } \\
\text { sobre } \\
\text { Empreendedorismo. }\end{array}$ & $\begin{array}{l}\text { Etkowitz, Webster, Gebhardt e Terra (2000); Dahlstrand, (2007); } \\
\text { Ferreira, Soria e Closs (2012); Aranha, Garcia, (2013); Tornatzky e } \\
\text { Rideout (2014); Chen, Hsiao, Chang, Chou, Chen, Shen, (2015); } \\
\text { Habibov, Afandi, Cheung, (2016); Ortega (2016); Júnior, Autio, } \\
\text { Morini, Gimenez e Dionísio, (2016); Jabeen, Faisal, Katsiooloudes, } \\
\text { (2017) }\end{array}$ \\
\hline $\begin{array}{c}\text { Suporte } \\
\text { especializado }\end{array}$ & $\begin{array}{l}\text { Eventos, palestras, } \\
\text { competições, } \\
\text { consultorias } \\
\text { mentorias }\end{array}$ & $\begin{array}{l}\text { Plonski (1999); Etkowitz (2003); Etkowitz (2004); Tornatzky e } \\
\text { Rideout (2014); Chais e Machado (2015); Ortega (2016); Júnior, } \\
\text { Autio, Morini, Gimenez e Dionísio, (2016) }\end{array}$ \\
\hline
\end{tabular}

Fonte: próprio autor (2017)

Propôs-se, então, uma união entre dois modelos não-causais, à parte do modelo causal de Gnyawali e Fogel (1994) que trata especificamente das características pessoais do empreendedor. As forças ambientais que atuarão sobre o indivíduo - nesse caso, as Universidades e suas ações de fomento ao empreendedorismo -, foram postas pelo modelo de
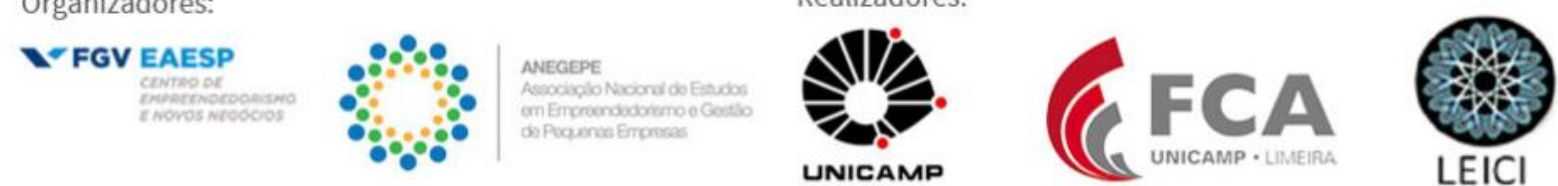
Isenberg (2011), localizadas no que o autor classifica como domínio de Capital Humano. As ações neste domínio serão regidas pelas três categorias- apoio técnico, estrutura física e suporte especializado -, conduzindo maiores ou menores habilidades empreendedoras e de gestão, que irão influenciar, em maior ou menor grau, a geração de novos negócios de base tecnológica.

Figura 2 - Modelo teórico proposto

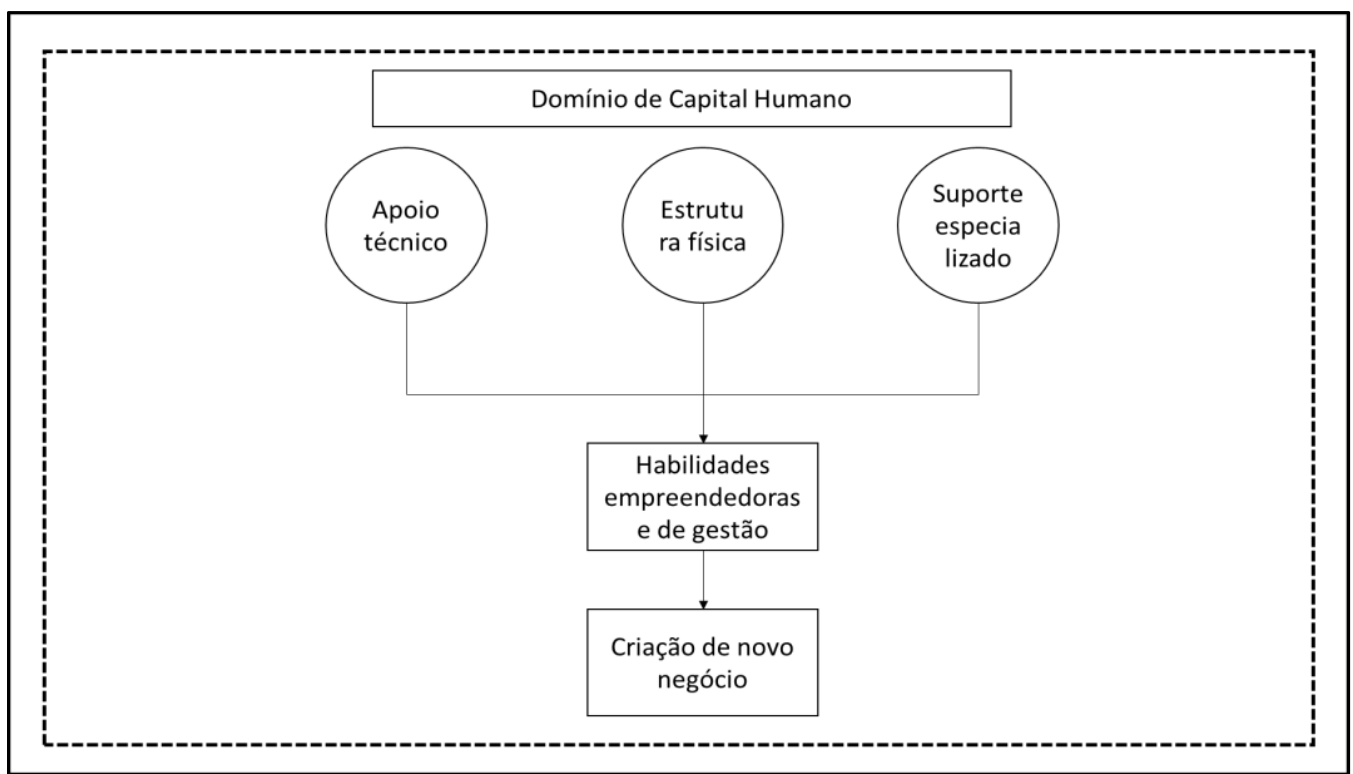

Fonte: adaptado de Gnyawali e Fogel (1994); Isenberg (2011) e Foster e Shimizu (2013)

\section{Metodologia}

A abordagem utilizada foi de natureza qualitativa, representada por Denzin e Lincoln (2000) como uma perspectiva naturalista e de interpretação do mundo ao redor do pesquisador, interpretando-o a partir dos significados que os indivíduos dão ao mesmo. Ademais, a pesquisa qualitativa no campo do empreendedorismo auxilia na compreensão do fenômeno, além de ser alternativa à pesquisa monocrática quantitativa no campo (Suddaby, Bruton \& Si, 2015).

Quanto ao método, o formato escolhido foi o estudo de caso descritivo. Um estudo de caso pode ser definido como uma análise de fenômenos sociais específicos, em determinado tempo e localidade, sendo relativamente delimitados (Ragin \& Becker, 1992). A unidade empírica de análise foi um empreendimento de base tecnológica - conceitualmente reconhecido como start-up - estabelecido em Belo Horizonte, tendo como sócio empreendedor um ex-aluno da Universidade Federal de Minas Gerais, caracterização exibida no Quadro 3.

Além da revisão de literatura necessária para a exploração dos conceitos relacionados a ecossistema empreendedor e universidade empreendedora, foram utilizados como instrumentos de coleta de dados a entrevista em profundidade com o empreendedor da startup e a análise documental da Universidade Federal. Conforme ressaltam Eisenhardt e Grabner (2007), a entrevista em profundidade é considerada a fonte primária de dados dentre os meios
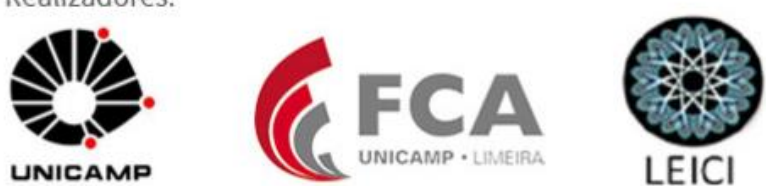
possíveis em um estudo de caso - dentre eles os arquivos, observações e levantamentos -, resultando em ricos dados empíricos. Já a análise documental, Yin (2005) ressalta que faz parte das possibilidades de estratégias para coleta de evidências em um estudo de caso, alavancando a qualidade conforme estes são triangulados.

\section{Quadro 3 - Caracterização da Empresa Pesquisada}

\begin{tabular}{|c|l|l|l|l|}
\hline $\begin{array}{c}\text { Ano de } \\
\text { Fundação }\end{array}$ & $\begin{array}{c}\text { No de } \\
\text { Funcionários }\end{array}$ & $\begin{array}{c}\text { Faturamento Anual } \\
\text { (Previsto) }\end{array}$ & $\begin{array}{c}\text { Sócios } \\
\text { Fundadores }\end{array}$ & Formação e demais informações \\
\hline 2013 & $\begin{array}{l}\text { Mais de 150 } \\
\text { funcionários } \\
\text { diretos }\end{array}$ & $\begin{array}{l}\text { Acima de R\$ } 60 \\
\text { milhões em 2017 }\end{array}$ & 2 & $\begin{array}{l}\text { Entrevistado: 32 anos, graduado em } \\
\text { Relações Públicas - UFMG } \\
\text { Sócio: 32 anos, graduado em } \\
\text { Engenharia de Produção - UFMG }\end{array}$ \\
\hline
\end{tabular}

Fonte: dados da pesquisa (2017)

\section{Descrição e Análise dos dados \\ 4.1 A universidade}

A Universidade alvo da pesquisa documental, UFMG, está localizada na cidade Belo Horizonte e região metropolitana, cidade que apresenta atualmente um dos maiores ecossistemas empreendedores do país, de aspecto colaborativo, com mais de 400 empreendimentos que ultrapassam a marca dos milhões de reais em investimentos e faturamento conjunto (Aguilhar, 2015; Amaral, 2016).

A UFMG, fundada em 1927, possui 20 unidades acadêmicas distribuídas em três campi. Com mais de 65 mil estudantes e 3.150 docentes, conta também com um vasto número de servidores técnico-administrativos. As atividades de inovação são coordenadas por um Núcleo de Inovação Tecnológica que gerencia a propriedade intelectual, ações de fomento ao empreendedorismo e incubação de empresas há mais de 20 anos. A UFMG ostenta o título de maior depositante de patentes do país, com mais de 170 patentes depositadas nos últimos dois anos. (Aguiar, 2017)

Além dos números expressivos em licenciamentos - 29 apenas em 2015 -, depósitos de patentes internacionais - 20 em 2017 -, a Universidade gerou mais de $\mathrm{R} \$ 650.000,00 \mathrm{em}$ ganhos econômicos advindos das atividades ligadas à inovação no último ano de 2017. Além desses números expressivos, a instituição promove competições empreendedoras, eventos em parceria com grandes organizações nacionais e multinacionais, além de relacionamento institucional com outras Universidades internacionais de renome. A gestão de um parque tecnológico em parceria com o poder público também é destaque (CTIT UFMG, 2018).

\subsection{Empreendimento de base tecnológica}

A empresa - aqui caracterizada como Alfa - está situada em Belo Horizonte. Com o início das operações em 2013, a organização exibe um modelo de negócio pautado na repetição e escalabilidade (Blank, 2010), operando uma plataforma digital de transação de milhagens aéreas, dependendo de tecnologia para seu desenvolvimento e sobrevivência (Dahlstrand, 2007). Atualmente a organização já conta com mais de 150 funcionários e faturamento anual acima de 60 milhões de reais.

Além das características definidoras citadas acima, a organização também segue outros padrões das empresas nascentes de base tecnológica, como a necessidade de financiamento externo e inauguração por um time fundador de alta escolaridade (Dahlstrand,
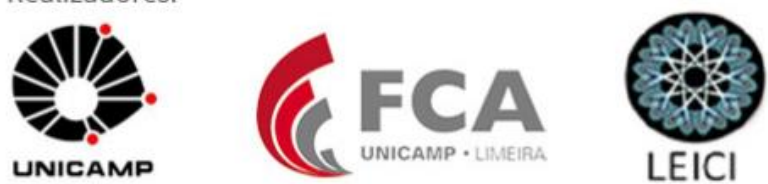
2007); empreendedores jovens de ambição e independência de outras empresas quando da fundação do empreendimento (Bollinger, Hope \& Utterback, 1983); frequentemente sujeita a mudanças e atuando em um ambiente dinâmico (FINEP, 2016); que iniciaram a partir de problemas detectados no mercado, e, utilizando tecnologias existentes em modelos de negócio inovadores, buscaram a solução de tais problemas (Etkowitz, 2001).

Iniciando a análise do empreendimento a partir do modelo teórico estabelecido, a estrutura física da universidade - incubadora, aceleradora, co-workings, salas de estudo e extensão -, não foram reconhecidos como presentes para o desenvolvimento da empresa, na avaliação do entrevistado. Os sócios, apesar de graduados na UFMG em Relações Públicas e Engenharia de Produção, não participaram de processos de incubação ou aceleração na Universidade. A única oportunidade na categoria estrutura física identificada foi a participação de um dos sócios em projeto de extensão universitária, mas não vinculada à startups ou à formação de um novo empreendimento. A participação no projeto de extensão tampouco levou à uma iniciação empreendedora, percepção de oportunidades ou vontade de empreender: "eu duvido que mudaria alguma coisa se tivesse participado ou não" (Dados da pesquisa, 2017).

A parceria com uma aceleradora - na época a maior aceleradora da América Latina -, foi decorrência de uma negociação pessoal, sem a intervenção ou participação da Universidade. Em meados de 2014 e com as operações já estabilizadas, os recursos financeiros da aceleradora não foram essenciais à consolidação da start-up na visão do empreendedor, mas reconhece o aprendizado com a participação na aceleradora. "Num sei se a gente estaria muito diferente do que tá hoje não. Mas com relação ao aprendizado, de contatos [...] eles ajudaram muito" (Dados da pesquisa, 2017).

O aprendizado obtido no processo de aceleração - que durou cerca de 3 a 4 meses -, demonstra uma possível ausência, da universidade, na oferta da segunda categoria apresentada no modelo teórico: o apoio técnico. Temas que, a princípio, poderiam ter sido tratados em cursos de empreendedorismo na grade curricular do curso de graduação e/ou mesmo em cursos extra-classe sobre o mesmo tema, foram oferecidos pela aceleradora, como, por exemplo, ensinamentos sobre uso de plataforma digital, questões jurídicas, além de conselhos e apoio para contratações de funcionários para a start-up. $\mathrm{O}$ empreendedor acrescenta que não adquiriu os conhecimentos gerenciais básicos- tais como, marketing e financeiro -, durante a graduação, mas em um estágio possibilitado pela Universidade. Entretanto, cabe ressaltar que a ausência de conhecimentos gerenciais que poderiam estar atrelados aos cursos e treinamentos foram sentidos negativamente durante a trajetória da empresa: "Não ter investido em gestão realmente foi um negócio que prejudicou a gente [...] A gente teria crescido muito mais, podia tá em outro patamar se tivesse conhecimento de gestão" (Dados da pesquisa, 2017).

Outro ponto de destaque sobre a graduação concluída na UFMG, foi a percepção do empreendedor, próxima ao que relatam Etkowitz et al. (2000) e Habibov, Afandi e Cheung (2016), acerca da preponderância no ensino universitário de aspectos técnicos que levem os alunos à adotarem uma carreira pública em instituições governamentais: "eu tenho a impressão de que ensina a gente a seguir carreira acadêmica e fazer concurso público, pra ser bem sincero" (Dados da pesquisa, 2017).

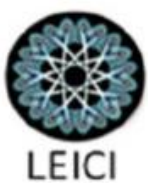


Analisando a última categoria do modelo teórico, o suporte especializado, a empresa Alfa, apesar de não ter contratado consultorias nem de empresa júnior nem de docentes para criação e gestão da empresa, participou de eventos, como o Start-up Brasil. Entretanto, tal evento, apesar de ser parceiro de instituições de fomento ao ensino e pesquisa, como o CNPq, não possui vínculo direto com universidades. Na avaliação do entrevistado, as mentorias que a empresa recebeu foram possibilitadas pela aceleradora a qual estavam vinculados. Atualmente, cinco anos após o início das operações, o próprio empreendedor é mentor de competições e eventos que reúnem start-ups em busca de recursos e aprendizado em todo o Brasil. Dessa dinâmica de ensino e aprendizagem, a partir dos eventos do setor, se destaca a possibilidade do ecossistema empreendedor fomentar novas parcerias e conhecimentos, que acabam por facilitar a geração e operação de inúmeros novos negócios: "Porque você entra nesse mundo, você acaba conhecendo muita gente. Assim, num é clubezinho [...] essas micro ajudas acontecem o tempo todo nesse meio [...] entre os mentores lá, eu conheço gente que acaba ajudando." (Dados da pesquisa, 2017).

Por fim, apesar de ressaltar que possui um vínculo fraco e pontual com Universidades, o empreendedor salienta que, apesar da atual distância, não somente ele, mas todo o ecossistema empreendedor - mais especificamente, o de Belo Horizonte - mantêm-se aberto para que esse vínculo se torne maior. "A UFMG me chamou pra poder dar uma palestra lá, um tempo atrás [...] mas são coisas bem pontuais, nada muito profundo não [...] o primeiro passo é a universidade querer. Se a universidade quiser, cara, eu garanto, o San Pedro Valley tá todo aberto" (Dados da pesquisa, 2017).

\section{Considerações finais}

Os dados obtidos na pesquisa de campo a partir da entrevista e análise documental representam informações iniciais sobre a relação e a contribuição da universidade na consolidação de um ecossistema empreendedor em Belo Horizonte. Na verdade, são dados parciais da pesquisa, já que esta encontra-se em andamento e prevê a análise mais ampla da relação entre empresas de base tecnológica e as instituições universitárias do Estado. A partir da literatura pesquisada constatou-se que as Universidades possuem papel de destaque nos modelos de ecossistemas, colaborando diretamente para a formação não só de novos empreendimentos de alto crescimento, mas também de empreendedores potenciais.

Da mesma forma, a partir da produção teórica que discute a Universidade Empreendedora, foi possível identificar o papel e as ações das Universidades para que possam ampliar sua missão original e contribuir, em parceria com governo e empresas, para o desenvolvimento econômico. Através da conjugação dessas perspectivas, analisou-se a relação de Universidade que atua na capital mineira, como um dos componentes do ecossistema empreendedor, com um empreendimento de base tecnológica - start-up -, estabelecido por um de seus ex-alunos.

A análise dos dados nos permitiu identificar que, dentre três categorias principais que exemplificam os projetos e ativos que as Universidades possuem para fomentar o empreendedorismo - estrutura física, apoio técnico e suporte especializado -, o resultado geral fica aquém daquele que a instituição de ensino demonstra em outros indicadores. Durante a análise do caso da empresa Alfa, foi possível perceber que, mesmo considerando os números significativos em licenciamento, patentes e ganhos econômicos advindos das atividades de inovação, a UFMG não é percebida, pelo empreendedor entrevistado, como tendo ações

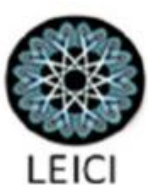


significativas no que tange ao ensino empreendedor e apoio na identificação de empreendimentos de alto impacto. Em outras palavras, na lista de apoios apontados pela literatura como oferecidos pela universidade, o empreendedor não reconhece que suas competências e ativos possam ter sido adquiridos a partir do seu período na Instituição Universitária. Essa constatação nos leva a refletir se as Universidades não tem sido pouco empreendedoras no sentido de mostrar, com mais clareza, para seu público interno como também para o externo, sua contribuição para o ecossistema empreendedor.

Os dados em termos de número de patentes, licenciamentos, a existência de incubadora e parque tecnológico no seu espaço, só para citar alguns elementos facilitadores do processo empreendedor, nos revelam que isso tem sido mal divulgado e trazido pouco retorno para a Instituição em termos de sua imagem e papel no ecossistema empreendedor de Belo Horizonte.

\section{Referências}

Aguiar, C. (2017, Maio 02). Entrevista: inovação e patentes aproximam universidades do setor produtivo. Disponível em: http://nit.uemg.br/?p=1007

Aguilhar, L. (2015, Março 01). Cooperação une startups da cena de San Pedro Valley em BH. Estadão. Disponível em: http://link.estadao.com.br/noticias/geral,cooperacao-une-startups-dacena-de-san-pedro-valley-em-bh,10000029631

Amaral, S. (2016, Julho 26). BH se consolida como ecossistema de startups; em Minas já são mais de 400. Hoje em Dia. Disponível em: http://hojeemdia.com.br/primeiro-plano/bh-se-consolidacomo-ecossistema-de-startups-em-minas-j\%C3\%A1-s\%C3\%A3o-mais-de-400-1.392202.

Anderson, A.; Ronteau, S. (2017). Towards an entrepreneurial theory of practice; emerging ideas for emerging economies. Journal of Entrepreneurship in Emerging Economies, 9(3), 110-120. Disponível em: http://www.emeraldinsight.com/doi/abs/10.1108/JEEE-12-2016-0054

Aranha, E, A. \& Garcia, N. A. P. (2013). A análise da universidade empreendedora no contexto brasileiro. ReFAE - Revista da Faculdade de Administração e Economia, 5(1), 101-126. Disponível em: https://www.metodista.br/revistas/revistasims/index.php/ReFAE/article/viewFile/3823/3733

Arruda, C.; Nogueira, V. S.; Cozzi, A.; Costa, V. (2015). The brazilian entrepreneurial ecosystem of startups: na analysis of entrepreneurship determinants in Brazil and the perceptions around the brazilian regulatory framework. Entrepreneurship in BRICS. 9-25. Disponível em: https://link.springer.com/chapter/10.1007/978-3-319-11412-5_2

Blank, S. (2010). What's a startup? First principles. Disponível em: https://steveblank.com/2010/01/25/whats-a-startup-first-principles/

Bollinger, L.; Hope, K.; Utterback, J. M. (1983). A review of literature and hypotheses on new technology-based firms. Research policy, 12. 1-14. Disponível em: http://www.sciencedirect.com/science/article/pii/0048733383900239

Chais, C.; Machado, C. (2015). Universidade empreendedora: a ótica dos empresários sobre o posicionamento empreendedor da universidade na contribuição para o desenvolvimento regional. Revista Gestão Universitária na América Latina, 8(4), 57-76. Disponível em: http://www.redalyc.org/pdf/3193/319343257005.pdf

Chen, S.; Hsiao, H.; Chang, J.; Chou, C.; Chen, C.; Shen, C. (2015). Can the entrepreneurship course improve the entrepreneurial intentions of students?. International Entrepreneurship

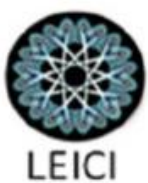


Management Journal, 11, 557-569. Disponível em: https://link.springer.com/article/10.1007\%2Fs11365-013-0293-0

Clark, B. R. (2001). The entrepreneurial university: new foundations for collegiality, autonomy, and achievement. Journal of the Programme on Institutional Management in Higher Education, 13(2), 9-25. Disponível em: http://www.oecd.org/edu/imhe/37446098.pdf

Clark, B. R. (2006). Pursuing the entrepreneurial university. In: Audy, J; Morosini, M. (org.) Innovation and entrepreneurialism in the university. EDIPCURS, Porto Alegre. (p. 15-27). Disponível em: http://www.pucrs.br/wpcontent/uploads/2016/02/inovacaoeempreendedorismo.pdf

Coordenadoria de Transferência e Inovação Tecnológica. (2018). Relatório de atividades 2017. Disponível em: http://www.ctit.ufmg.br/publicacoes-e-editais/

Dahlstrand, A. L. (2007) Technology-based entrepreneurship and regional development: the case of Sweden. European Business Review, 19(5), 373-384. Disponível em: http://www.emeraldinsight.com/doi/abs/10.1108/09555340710818969

Denzim, N., K.; Lincoln, Y., S. (2000) Handbook of Qualitative Research. London: Sage Publications

Dubois, A.; Gibbert, M. (2010). From complexity to transparency: managing the interplay between theory, method and empirical phenomena in IMM case studies. Industrial Marketing Management, 39, 129-136.

Einsenhardt, K., Graebner, M. (2007). Theory building from cases: opportunities and challenges. Academy of Management Journal, 60(1), 25-32.

Etkowitz, H.; Leydesdorff, L. (2000). The dynamics of innovation: from National Systems and "Mode 2" to a Triple Helix of university-industry-government relations. Research Policy, 29, 109-123. Disponível em: http://www.oni.uerj.br/media/downloads/1-s2.0-S00487333399000554main.pdf

Etkowitz, H.; Webster, A.; Gebhardt, C.; Terra, B. R. C. T. (2000). The future of the university and the university of the future: evolution of ivory tower to entrepreneurial paradigm. Research Policy, 29, 313-330. Disponível em: http://www.oni.uerj.br/media/downloads/1-s2.0S0048733399000694-main.pdf

Etkowitz, H. (2001). The second academic revolution and the rise of entrepreneurial Science.IEEE Technology and Society Magazine, 2011. Disponível em: http://ieeexplore.ieee.org/document/948843/

Etkowitz, H. (2003). Research groups as 'quase-firms': the invention of the entrepreneurial university. Research Policy, 32, 109-121. Disponível em: http://www.oni.uerj.br/media/downloads/1-s2.0-S0048733302000094-main.pdf

Etkowitz, H. (2004). The evolution of the entrepreneurial university. International Journal of Technology and Globalization, 1(1), 64-78. Disponível em: https://www.inderscienceonline.com/doi/abs/10.1504/IJTG.2004.004551

Ferreira, G. C.; Soria, A. F.; Closs, L. (2012). Gestão da interação universidade-empresa: o caso PUC-RS. Revista Sociedade e Estado, 27(1), 79-93. Disponível em: http://www.scielo.br/scielo.php?script=sci_arttext\&pid=S0102-69922012000100006

FINEP (2017) Glossário. Disponível em: http://www.finep.gov.br/biblioteca/glossario

Foster, G.; Shimizu, C. (2013). Entrepreneurial ecosystems around the globe and company growth dynamics. In Annual Meeting of the New Champions 2013 (pp. 1-36). Disponível em: http://www3.weforum.org/docs/WEF_EntrepreneurialEcosystems_Report_2013.pdf 
Gibb, A. (2002). In pursuit of a new 'entrepreneurship' paradigma for learning: creative destruction, new values, new ways of doing things and new combinations of knowledge. International Journal of Management Reviews, 4(3), 233-269. Disponível em: http://onlinelibrary.wiley.com/doi/10.1111/1468-2370.00086/abstract

Gnyawali, D. R.; Fogel, D. S. (1994) Environments for entrepreneurship development: key dimensions and research implications. Entrepreneurship Theory and Practice, 43-60. Disponível em:

https://www.researchgate.net/publication/263733348_Environment_for_Entrepreneurship_Develo pment_Key_Dimensions_and_Research_Implications

Habibov, N.; Afandi, E.; Cheung, A. (2016). What is the effect of university education on chances to be self-employed in transitional countries? Intrumental variable analysis of cross-sectional sample of 29 nations. International Entrepreneurship Management Journal, 1-13. Disponível em: https://link.springer.com/article/10.1007/s11365-016-0409-4

Ingstrup, M. B.; Freytag, P. V.; Damgaard, T. (2009). Cluster initiation and development: a critical view from a network perspective! In IMP 2009 Conference at Euromed Management (pp. 1-19). França.

Isenberg, D (2010). How to start an entrepreneurial revolution. Harvard Business Review. Disponível em: https://hbr.org/2010/06/the-big-idea-how-to-start-an-entrepreneurial-revolution Isenberg, D. (2011). The entrepreneurship ecosystem strategy as a new paradigm for economy policy: principles for cultivating entrepreneurship. The Babsom Entrepreneurship Ecosystem Project.

Isenberg, D. (2016). Applying the ecosystem metaphor to entrepreneurship: uses and abuses. The Antitrust Bulletin, 61(4), 564-574. Disponível em: http://journals.sagepub.com/doi/abs/10.1177/0003603X16676162

Jabeen,F.; Faisal, M. N.; Katsioloudes, M. I. (2017). Entrepreneurial mindset and the role of universities as strategic drivers of entrepreneurship: evidence from the United Arab Emirates. Journal of Small Business and Entreprise Development. 24(1), 136-154. Disponível em: http://www.emeraldinsight.com/doi/abs/10.1108/JSBED-07-2016-0117

Júnior, E., I.; Autio, E.; Morini, C.; Gimenez, F., A., P.; Dionisio, E., A. (2016). Analysis of the brazilian entrepreneurial ecosystem. Desenvolvimento em questão. 37. 5-36. Disponível em:https://www.revistas.unijui.edu.br/index.php/desenvolvimentoemquestao/article/view/6253

Mason, C.; Brown, R. (2014). Entrepreneurial ecosystems and growth oriented entrepreneurship. In LEED Programme and the Dutch Ministry of Economic Affairs (pp. 1-30). Disponível em: http://www.oecd.org/cfe/leed/entrepreneurial-ecosystems.pdf

Murovec, N.; Prodan, I. (2009). Absorptive capacity, its determinants, and influence on innovation output: cross-cultural validation of the structural model. Technovation, 29, 859-872. Disponível em: https://www.sciencedirect.com/science/article/pii/S0166497209000844

OECD. (2011). Indicators of entrepreneurial determinants. Disponível em: http://www.oecd.org/industry/business-stats/indicatorsofentrepreneurialdeterminants.htm Ortega, L. M. Programa empreendedorsimo-escola: influenciando a universidade por meio do tripé ensino, pesquisa e extensão (2016). RACEF - Revista de Administração, Contabilidade e Economia da Fundac,7(1), 118-131. Disponível em: https://www.fundace.org.br/revistaracef/index.php/racef/article/view/189/pdf_11

Philpott, K.; Dooley, L.; O'Reilly, C.; Lupton, G. (2011). The entrepreneurial university: examining the underlying academic tensions. Technovation, 31, 161-170. 
Premand, P.; Brodmann, S.; Almeida, R.; Grun, R.; Barouni, M. (2016). Entrepreneurship education and entry into self-employment among university graduates. World Development, 77, 311-327.

Disponível

em:

http://documents.worldbank.org/curated/en/205601468334874186/pdf/wps6285.pdf

Ragin, C. (1992) Introduction: cases of "what is a case?”. In: Ragin e Becker (1992), What is a case? (p. 1-17). Cambridge: Cambridge University Press

Saxenian, A. (1990). Regional Networks and the resurgence of Silicon Valley. California Management Review. 89-109. Disponível em: http://www1.ximb.ac.in/users/fac/visiting/vfac.nsf/23e5e39594c064ee852564ae004fa010/51e213 743b63ce6e65257028003e3ccc/\$FILE/saxenian.pdf

SEBRAE (2016). Empreendedorismo nas universidades brasileiras. Disponível em: https://m.sebrae.com.br/Sebrae/Portal\%20Sebrae/Anexos/Relatorio\%20Endeavor\%20impressao.p df

Suddaby, R.; Bruton, G. D.; Steve, X. S. (2015). Entrepreneurship through a qualitative lens: insights on the construction and/or discovery of entrepreneurial opportunity. Journal of Business Venturing, 30, 1-10.

Tornatzky, L. G.; Rideout, E. C. (2014). Innovation U 2.0: reinventing university roles in a knowledge economy. Disponível em: http://www.innovation-u.com/InnovU-2.0_rev-12-14-14.pdf Yin, R., K. (2005). Projetando estudos de caso. In Yin (2005), Estudo de caso: planejamento e método (p. 39-79). Porto Alegre: Bookman.

Zarate-Hoyos, G.A.; Larios-Meoño, F. (2015). The role of universities and other institutions in successful entrepreneurship: soe insights from a literature review. Propósitos y Representaciones, 3(2), 261-317. Disponível em: http://files.eric.ed.gov/fulltext/EJ1126313.pdf 